\title{
DIÁLOGOS ENTRE A FUNÇÃO ARQUIVÍSTICA DE AVALIAÇÃO E A REPRESENTAÇÃO DA INFORMAÇÃO
}

\section{DIALOGUES BETWEEN THE ARCHIVAL APPRAISAL FUNCTION AND THE REPRESENTATION OF THE INFORMATION}

\author{
Camila Schwinden Lehmkuhla \\ Evelin Melo Mintegui ${ }^{b}$ \\ Eva Cristina Leite da Silvac \\ Marisa Bräscher Basílio Medeiros ${ }^{\mathrm{d}}$
}

\begin{abstract}
RESUMO
Introdução: Com a alteração de seu objeto de estudo, de conjunto de documentos para o conjunto de informações orgânicas, a Arquivologia assiste novas interlocuções teórico-metodológicas com distintas disciplinas que também possuem como objeto a informação, como a Ciência da Informação e a Organização do Conhecimento e da Informação. Nessa perspectiva, a presente pesquisa parte da problemática de analisar se a Organização e Representação da Informação podem ser observadas dentro da Arquivologia, principalmente no tocante a função arquivística de avaliação de documentos. Objetivo: Demonstrar relações entre a função de avaliação arquivística e a representação da informação, a partir da ISDF. Metodologia: pesquisa exploratória e qualitativa. Resultados: ao fazer o paralelo entre a avaliação de documentos, a ISDF e a Representação da Informação é possível identificar que a ISDF contribui para a avaliação arquivística, a partir da descrição das funções da instituição, descrição essa, entendida aqui como representação da informação arquivística. Conclusão: essa pesquisa demonstrou que os diálogos podem ser observados e procurou instigar a comunidade acadêmica para o assunto e para o desenvolvimento de novas pesquisas relacionadas ao processo de avaliação e a representação da informação.
\end{abstract}

Descritores: Organização da Informação. Arquivologia. Função arquivística de avaliação. Norma Internacional de Descrição de Funções.

a Doutoranda no Programa de Pós-Graduação em Ciência da Informação (PGCIN) da Universidade Federal de Santa Catarina (UFSC). E-mail: camila_lehmkuhl@hotmail.com

b Doutoranda no Programa de Pós-Graduação em Ciência da Informação (PGCIN) da Universidade Federal de Santa Catarina (UFSC). E-mail: eminteguimail@gmail.com

c Docente no Programa de Pós-Graduação em Ciência da Informação (PGCIN) da Universidade Federal de Santa Catarina (UFSC). E-mail: eva.cristina@ufsc.br

d Docente no Programa de Pós-Graduação em Ciência da Informação (PGCIN) da Universidade Federal de Santa Catarina (UFSC). E-mail: marisa.brascher@gmail.com 


\section{INTRODUÇÃO}

Entre as disciplinas que vêm dialogando com a Arquivologia em sua busca por dar conta dos processos sociais de guarda e uso de documentos, destacase a Organização e Representação da Informação (ORI). Nesse sentido, sobressaem-se suas correlações com as funções de classificação e descrição arquivísticas, já que a necessidade de recuperação da informação está implicitamente envolvida nesses processos específicos.

A problemática deste trabalho parte do seguinte questionamento: a ORI pode contribuir para o desempenho de outras funções arquivísticas? Parte-se do pressuposto de que a função arquivística de avaliação pode ser uma função correlata à ORI. Uma referência a essa possibilidade é encontrada na Norma Internacional de Descrição de Funções (International Standard for Describing Functions - ISDF). A norma é um dos quatro padrões internacionais propostos pelo Conselho Internacional de Arquivos (CIA), entre os quais figuram ainda a Internacional Standard for Archival Description (ISAD-G), a International Standard for Description for Institutions with Archival Holdings (ISDIAH) e a International Standard Archival Authority Record for Corporate Bodies, Persons and Families (ISAAR- CPF) 1 . Além de afirmar a centralidade do conhecimento das funções para classificação, descrição e indexação nos arquivos, a ISDF acrescenta, ainda, o quão apropriado ele se apresenta para servir de base à avaliação de documentos.

Este trabalho tem como objetivo geral demonstrar relações entre a função de avaliação arquivística e a representação da informação, a partir da ISDF. Uma vez que a avaliação de documentos de arquivo compreende um processo que reúne teorias, instrumentos e planos de ação. Foi preciso utilizar um modelo que permita explicar as circunstâncias em que a norma ISDF pode ser utilizada na função arquivística de avaliação. $O$ modelo escolhido foi o apresentado por

\footnotetext{
${ }^{1}$ Embora já exista iniciativa em andamento no intuito de integrar todas essas representações sobre instituições, pessoas, famílias e seus documentos (como é o caso do Records In Context - RIC), ela ainda não foi apresentada em sua versão final, e, por isso, não é discutida neste trabalho.
} 
Hernandez Olivera e Moro Cabero (2002), que contribui com a visualização das atividades e tarefas envolvidas na avaliação de documentos de forma clara. Dessa forma, os objetivos específicos são: a) Apontar diálogos assistidos acerca das funções arquivísticas e a Representação da Informação; b) Apresentar a ISDF enquanto subsídio/ferramenta para o processo de avaliação de documentos, a partir do modelo do processo de avaliação das autoras Hernandez Olivera e Moro Cabero (2002); c) Identificar, com base na ISDF e o modelo de aplicação de avaliação diálogos entre a Representação da Informação e a função arquivística de avaliação.

Inicia-se com uma breve consideração sobre a relação da ORI com a Arquivologia. Em seguida, apresenta-se a ISDF, norma de descrição arquivística de funções. A seguir, define-se a função arquivística de avaliação e algumas de suas abordagens. A metodologia é de tipo exploratória, uma vez que tem como objetivo proporcionar maior familiaridade com o problema, com abordagem qualitativa, cuja fonte foi selecionada por sua relevância para a temática. Logo, expõe-se um modelo de procedimentos de avaliação de documentos de arquivo, a partir do qual se propõe o uso da descrição de funções, e por conseguinte, da representação da informação, no processo de avaliação de documentos de arquivo.

\section{AS RELAÇÕES ENTRE REPRESENTAÇÃO DA INFORMAÇÃO E A ARQUIVOLOGIA}

Para contextualizar brevemente as correlações entre ORI e Arquivologia, é necessário fazer menção à Organização do Conhecimento $(\mathrm{OC})$. A OC é referida ora como área relativamente autônoma da Ciência da Informação (ALVES; OLIVEIRA, 2016), ora como ciência propriamente dita (DAHLBERG, 2006), sendo resultado de diversos fenômenos de desenvolvimento teórico que envolvem a biblioteconomia e a documentação ou associada a atividades geralmente práticas envolvendo o tratamento de documentos e informações no sentido amplo, o que a remeteria à Antiguidade (GOMES, 2017). A OC poderia servir como referência de um grande campo interessado em possibilitar acesso 
ao conteúdo de documentos em geral.

Para Hjorland (2008), a OC pode ser definida em sentido estrito e em sentido amplo. A primeira dessas definições estaria relacionada às atividades de descrição e representação, criação de sistemas de organização do conhecimento e teria como ponto de partida os saberes do campo da Library and Information Science (LIS). No sentido amplo, a OC teria relação com os sistemas de divisão social do trabalho mental realizadas pelas diversas instituições e demais disciplinas específicas em todos os campos do conhecimento. Assim, a OC no sentido amplo teria como disciplinas centrais de seu instrumental a sociologia do conhecimento, as próprias disciplinas a serem objeto da criação dos sistemas de classificação e a metafísica. Neste caso, a ORI estaria diluída na OC.

Para Bräscher e Café (2008) essa diferenciação aparece de forma mais clara: ORI trata-se do "processo que envolve a descrição física e de conteúdo dos objetos informacionais" enquanto ORC seria aquela que "visa à construção de modelos de mundo que se constituem em abstrações da realidade" (BRÄSCHER; CAFÉ, 2008), aplicada a unidades do pensamento (conceitos).

Em quaisquer dos pontos de vista, neste campo do conhecimento, a ideia de representação remete a "um processo pelo qual institui-se um representante que, em certo contexto limitado, tomará o lugar de quem representa" (MAKOWIECKY, 2003). Sua preocupação é a criação de "um conjunto de elementos descritivos que representam os atributos de um objeto informacional específico" (BRÄSCHER; CAFÉ, 2008).

No caso da Arquivologia, disciplina estruturada no final do Séc. XIX, que, em um primeiro momento, identifica-se como uma "ciência guardiã" de documentos, prezando pela preservação e conservação do suporte papel, a representação, embora já implícita em seus instrumentos pouco sofisticados, como listagens e índices, só passa a ter maior atenção com o desenvolvimento das tecnologias de informação, a partir da metade do Séc. XX. Assim, observase uma alternância de foco em seu objeto de estudo. Segundo Tognoli e Guimarães (2011, p. 24)

Antes entendido como um conjunto de documentos produzidos 
e/ou recebidos por uma pessoa física ou jurídica no desempenho de uma função específica, o objeto da disciplina passa a ser o conjunto de informações orgânicas, devido à expansão e mudanças tecnológicas observadas no final da década de 1980, quando se reconhece a informação como elemento estratégico central nas organizações e no Estado.

Um exemplo de autores que confirmam essa alteração são Rousseau e Couture (1998), quando afirmam a necessidade da Arquivologia e de seu novo objeto:

[...] a arquivística contemporânea tem obrigação de evoluir rapidamente, a fim de ocupar de maneira plena o seu lugar enquanto disciplina socialmente admitida, porque rendível e eficaz para os seus utilizadores (administradores, investigadores, etc.) e perfeitamente adaptada às necessidades de gestão da informação próprias do século XX (ROUSSEAU; COUTURE, 1998, p. 129).

Embora com objeto reformulado - do documento para a informação, Rousseau e Couture (1998) reafirmam núcleos de expertise dentro da disciplina arquivística, alguns deles mais ou menos integrados ao paradigma anterior que considerava objeto da Arquivologia os conjuntos de documentos. Esses núcleos são denominados funções, sendo elas: criação/produção, classificação, avaliação, aquisição, preservação/conservação, descrição e difusão/acesso.

Neste ponto, nos interessa definir duas dessas funções arquivísticas: classificação e descrição. Os significados dos conceitos de classificação e descrição arquivística podem variar dentro dos diferentes paradigmas e visões teóricas da área. De acordo com Sousa (2008), a classificação é a "atividade intelectual de construção de instrumentos para a organização dos documentos, independente da idade à qual eles pertençam" ou a construção de "esquemas para agrupar os documentos a partir de princípios estabelecidos”. Por sua vez, descrição "significa escrever sobre materiais de arquivo, e abrange as ideias de representação, identificação e organização"2 (DURANTI, 1993, tradução nossa). Para Llanes Padrón (2016), se em um primeiro momento a descrição seria considerada como criação de instrumentos de pesquisa (guias, inventários, etc.), numa perspectiva pós-moderna da Arquivologia a descrição está justamente

\footnotetext{
2 [...] means writing about archival material, and embraces the ideas of representation,
} identification and organization. 
mais relacionada com a representação da informação, além de incluir preocupações de manutenção da evidência no caso dos documentos digitais.

Essa alteração de objeto de estudo da Arquivologia, embora não seja consensual no campo, tem permitido a complementaridade da disciplina com a Organização da Informação. Entre os autores que partem desse ponto de vista, cita-se Barros (2016), para quem a classificação funciona como a base para todos os processos de organização de arquivos e evidentemente para a representação do conhecimento arquivístico.

[...] possibilita a existência de relações interdisciplinares entre a Arquivística e a Organização do Conhecimento, possibilitando a primeira abordagens teórico metodológicas constituindo um novo momento para a organização de arquivos e neste universo apropriar-se de metodologias de tratamento, como aquelas presentes nos processos de indexação (BARROS, 2016, p. 3940).

No mesmo sentido, Vital, Medeiros e Bräscher (2017) afirmam que "os processos de organização e representação da informação são desenvolvidos nos arquivos, especificamente, nas atividades de classificação e descrição arquivística". Complementam, ainda, demonstrando a pertinência dos planos de classificação como um instrumento de representação da realidade institucional, tanto quanto necessários para a representação dos próprios documentos enquanto objetos físicos, que, por sua vez, proverão elementos para o processo de descrição.

Ainda sobre a descrição arquivística, é pertinente considerar que a ORI nos arquivos não se restringe unicamente aos conjuntos documentais. A descrição arquivística também compreende representações sobre as instituições custodiadoras de acervos arquivísticos (ISDIAH), autoridades arquivísticas que geram e acondicionam fundos arquivísticos (ISAAR-CPF), além, é claro, da representação sobre o conteúdo dos documentos, especificidade (ISAD-G). Por sua vez, a ISDF propõe a descrição da atuação das entidades e pessoas, e da forma como elas desempenhavam suas atividades.

\section{A INTERNATIONAL STANDARD FOR DESCRIBING FUNCTIONS - ISDF}

A ISDF foi desenvolvida pelo Comitê de Boas Práticas e Normas do 
Conselho Internacional de Arquivos (CIA) em 2007, traduzida para o português em 2008 e distribuída pelo Arquivo Nacional como publicação técnica n. 52/2008. Ela "dá diretivas para a preparação de descrições de funções de entidades coletivas associadas à produção e manutenção de arquivos" (CONSELHO INTERNACIONAL DE ARQUIVOS, 2008), caracterizando de diversas formas o produtor dos documentos de arquivo.

No âmbito desta norma, uma função é entendida como:

Qualquer objetivo de alto nível, responsabilidade ou tarefa prescrita como atribuição de uma entidade coletiva pela legislação, política ou mandato. Funções podem ser decompostas em conjuntos de operações coordenadas, tais como subfunções, procedimentos operacionais, atividades, tarefas ou transações (CONSELHO INTERNACIONAL DE ARQUIVOS, 2008, p. 13).

Os elementos de descrição da ISDF apresentam quatro áreas de informação, acrescidas de diretrizes para relacionamentos com outros tipos de descrição existentes, sejam descrições de documentos (criadas com a ISAD-G) ou de autoridade (criadas com ISDIAH ou ISAAR-CPF), como é possível visualizar no Quadro 1, abaixo.

Quadro 1 - Elementos de descrição da ISDF

\begin{tabular}{|l|l|}
\hline Áreas & Elementos de Descrição \\
\hline $\begin{array}{l}\text { ÁREA DE } \\
\text { IDENTIFICAÇÃO }\end{array}$ & $\begin{array}{l}\text { Tipo; Forma(s) autorizada(s) do nome; Forma(s) } \\
\text { paralela(s) do nome; Outra(s) forma(s) do nome; } \\
\text { Classificação. }\end{array}$ \\
\hline $\begin{array}{l}\text { ÁREA DE } \\
\text { CONTEXTUALIZAÇÃO }\end{array}$ & Datas; Descrição; História; Legislação. \\
\hline $\begin{array}{l}\text { ÁREA DE } \\
\text { RELACIONAMENTOS }\end{array}$ & $\begin{array}{l}\text { Forma(s) autorizada(s) do nome/ldentificador da função } \\
\text { relacionada; Tipo; Categoria do relacionamento; } \\
\text { Descrição do relacionamento; Datas do relacionamento. }\end{array}$ \\
\hline ÁREA DE CONTROLE & $\begin{array}{l}\text { Identificador da descrição da função; Identificadores da } \\
\text { instituição; Regras e/ou convenções utilizadas; Status; } \\
\text { Nível de detalhamento; Datas de criação, revisão ou } \\
\text { obsolescência; Idioma(s) e forma(s) de escrita; Fontes; } \\
\text { Notas de manutenção. }\end{array}$ \\
\hline
\end{tabular}

Fonte: Conselho Internacional de Arquivos (2008).

A Área de Identificação permite que se crie o ponto de acesso normalizado 
para a função, através da nomenclatura escolhida para a função. A Área de Contextualização é destinada a alocar informações sobre o que é e como se desenvolve a função pela entidade. Por sua vez, a Área de Relacionamento reserva espaço para explicar os nexos da função com outras funções exercidas pela entidade. A Área de Controle destina-se ao monitoramento da própria representação realizada, permitindo o registro de onde, como e por quem a descrição foi realizada. Há, ainda, uma área extra, destinada ao relacionamento com outras entidades, materiais arquivísticos e recursos, que permitem contextualizar a ação da entidade para além de seu universo particular (CONSELHO INTERNACIONAL DE ARQUIVOS, 2008).

O produto dessa descrição resultante da aplicação da ISDF pode ter diversas aplicações no tratamento e uso das informações e dos arquivos: para o "arranjo, classificação e descrição de documentos", "como ferramenta para a recuperação e análise de documentos" e para a "avaliação de documentos" (CONSELHO INTERNACIONAL DE ARQUIVOS, 2008).

\section{A FUNÇÃO ARQUIVÍSTICA DE AVALIAÇÃO}

A função arquivística de avaliação é reconhecida como parte do núcleo duro da Arquivologia. Para Cook (2001), a avaliação "[...] explora, em um sentido filosófico, as fontes ou influências sobre as quais os arquivistas fundamentam suas decisões para atribuir 'valor' ou 'significado' ou 'importância' aos registros".

A ideia de que é necessário escolher documentos para guarda permanente não fazia parte do quadro conceitual da Arquivologia clássica, especialmente representada por Jenkinson, para quem a escolha dos documentos a preservar seria uma problemática do órgão produtor dos documentos, tendo o arquivista a tarefa de garantir que depois de tal escolha, nada seria alterado. É no contexto pós Segunda Guerra Mundial, de aumento do volume de documentos produzidos e de complexificação de estruturas administrativas, que a Arquivologia estenderia seu foco de atenção ao ciclo vital de documentos, expandindo também suas ferramentas conceituais (RIBEIRO, 2005). 
Schellenberg (2006), arquivista norte-americano, foi o criador das abordagens de valor primário e secundário para os documentos. Segundo o próprio autor:

Os valores inerentes aos registros públicos modernos são de dois tipos: valor primário para a gestão de criação e valor secundário para outras instâncias e utilizadores. Os documentos públicos são gerados para realizar as finalidades para as quais um organismo foi criado: administrativo, fiscal, legal e operacional. Os documentos públicos são preservados em uma instituição arquivística definida, porque têm um valor que existirá por longo tempo, mesmo depois que cessam de ser do uso corrente e porque terão valores importantes para outros usuários que não os atuais (SCHELLENBERG, 2006, p. 58).

Dessa forma, Schellenberg (2006) acredita que nem tudo precisa ser preservado e que o processo de avaliação dos documentos decidirá quais valores serão atribuídos aos documentos. Ainda, quanto à necessidade de haver avaliação, logo, eliminação documental em uma organização, Schellenberg (2006) salienta que:

Uma redução na quantidade de tais documentos torna-se essencial, tanto para o próprio governo quanto para 0 pesquisador. O governo não pode conservar todos os documentos produzidos em consequência de suas múltiplas atividades. Torna-se impossível prover espaço para armazenálos, bem como pessoal para cuidar dos mesmos (SCHELLENBERG, 2006, p. 179).

A função arquivística de avaliação tem sido, especialmente na tradição ibérica, constantemente tomada como sinônimo do processo de atribuição de valores primários ou secundários aos documentos. Entretanto, existem outras possíveis abordagens. Por exemplo, Ribeiro (2005), que critica os critérios de valor de Schellenberg (2006). A autora acredita que o próprio termo (avaliação) seria confuso, porque pode referir-se tanto ao desempenho dos serviços de informação, à eficácia e eficiência desses serviços ou ao fluxo de informação de uma organização. Para ela, a proposta de valoração do americano teria tido seus méritos na solução de muitos problemas da metade do séc. $X X$, mas seria por demais subjetiva, além de estar epistemologicamente ligada a um paradigma tecnicista. Em seu lugar, faz uma proposta embasada em um esquema quadripolar, que se diz capaz de avaliar o fluxo de informação, buscando a "detecção de redundâncias e desperdícios informacionais" (RIBEIRO, 2005). Os 
critérios, em lugar dos já citados valores primários e secundários, seriam pertinência, densidade e frequência de uso.

Por sua vez, Terry Cook, arquivista canadense, considera que a avaliação de documentos de arquivo deve ser feita em seu arcabouço macro, ou seja, em seu contexto mais amplo. A abordagem de macroavaliação se originou no final da década de 1980 dentro dos Arquivos Nacionais do Canadá e foi formalmente lançada através do governo federal canadense na primavera de 1991 (COOK, 2005). Para determinar esse "valor" dos documentos baseado em seu contexto, Cook apresenta três pontos de análise, ou como ele denomina "três entidades contextuais inter-relacionadas" que são:

1) os criadores de documentos (ou seja, estruturas, agências, instituições, burocratas), 2) os processos sócio-históricos (isto é, funções, programas, atividades, transações - serviços - que o Estado oferece aos cidadãos, e que os cidadãos demandam do governo) e 3) os cidadãos, clientes, constituintes, ou grupos, os quais estas funções e estruturas afetam, e que por sua vez influenciam tanto a função como a estrutura, direta ou indiretamente, explícita ou implicitamente (COOK, 2012, p. 150).

Um exemplo dessa macroavaliação pode ser encontrado nas políticas públicas de arquivo da Austrália. A partir da definição de alguns princípios, comissões de avaliação setoriais e central analisam a pertinência da guarda dos conjuntos documentais. No exemplo em questão e reproduzindo o que Cook (2012) aborda, eles são definidos como aqueles capazes de representar: a) a estrutura governamental e suas divisões, suas ações e transparência; b) identidade, interações e direitos; e c) conhecimento e memória da comunidade. Esse processo avaliativo leva à geração de listas de conjuntos documentais a serem preservados de forma permanente (NATIONAL ARCHIVES OF AUSTRALIA, 2019).

A escolha sobre a abordagem da função de avaliação arquivística também parece depender da concepção do tempo sobre o qual as decisões sobre a preservação de documentos devem ser tomada, seja considerando um ciclo de vida, seja considerando um continuum. Embora existam essas diferentes abordagens, a teoria dos valores documentais tem certa hegemonia, especialmente nos países sul-americanos. No Brasil, a teoria do valor está incorporada à sua política nacional de arquivos: 
Art. $8^{\circ}$ - Os documentos públicos são identificados como correntes, intermediários e permanentes.

$\S 1^{\circ}$ - Consideram-se documentos correntes aqueles em curso ou que, mesmo sem movimentação, constituam objeto de consultas freqüentes.

$\S 2^{\circ}$ - Consideram-se documentos intermediários aqueles que, não sendo de uso corrente nos órgãos produtores, por razões de interesse administrativo, aguardam a sua eliminação ou recolhimento para guarda permanente.

$\S 3^{\circ}$ - Consideram-se permanentes os conjuntos de documentos de valor histórico, probatório e informativo que devem ser definitivamente preservados (BRASIL, 1991, s.p.).

A avaliação de documentos, independente de sua abordagem teórica, precisa de procedimentos, atores e instrumentos para ser efetivada. Na teoria do valor, o instrumento apontado como mediador da avaliação de documentos de arquivo é a tabela de temporalidade, e sua construção e aplicação seria mediada por uma comissão de representantes dos órgãos produtores dos documentos, conduzida pelos responsáveis pela gestão arquivística de uma organização. Para que esse processo se torne palpável, buscou-se um modelo que apresentasse todos esses procedimentos e atores na construção e uso de uma tabela de temporalidade.

\section{POSSIBILIDADES DE USO DA ISDF EM UM MODELO DE PROCEDIMENTOS PARA AVALIAÇÃO DE DOCUMENTOS}

Para visualizar as possibilidades de uso da ISDF na avaliação de documentos, parte-se do modelo de um processo de avaliação de documentos desenvolvido por Hernandez Olivera e Moro Cabero (2002). Os autores propõem dez fases, sendo que em cada uma delas é possível identificar a entidade responsável pela ação, a operação para esta ação, bem como a definição dos registros que serão gerados por ela. Este modelo, além de definir uma sequência de passos necessários para a criação de um instrumento de temporalidade, torna possível a auditoria desse processo por meio dos registros, iniciativa que os torna passível de certificações de qualidade.

Tais entidades, fases, operações e registros podem ser visualizados no Quadro 2, abaixo. 


\section{Quadro 2 - Procedimentos técnicos de um processo de avaliação de documentos}

\begin{tabular}{|c|c|c|c|}
\hline Entidade & Fases & Operação & Documentação \\
\hline DIREÇÃO & 1 & $\begin{array}{l}\text { Criação de } \\
\text { comissão } \\
\text { de } \\
\text { avaliação }\end{array}$ & $\begin{array}{l}\text { Normativa externa e interna do } \\
\text { organismo titular da documentação; } \\
\text { Norma de criação da comissão de } \\
\text { avaliação. }\end{array}$ \\
\hline DIREÇÃO & 2 & $\begin{array}{l}\text { Nomeação } \\
\text { dos } \\
\text { membros da } \\
\text { comissão } \\
\text { de } \\
\text { avaliação }\end{array}$ & $\begin{array}{l}\text { Norma de criação da comissão de } \\
\text { avaliação; } \\
\text { Norma de designação da comissão } \\
\text { de avaliação. }\end{array}$ \\
\hline ARQUIVO & 3 & $\begin{array}{l}\text { Pesquisa } \\
\text { preliminar }\end{array}$ & $\begin{array}{l}\text { Inventário, documentação sobre as } \\
\text { séries, organograma, documentação } \\
\text { jurídica, planos de classificação, } \\
\text { tabelas de temporalidade; } \\
\text { Inventário conceitual e físico. }\end{array}$ \\
\hline $\begin{array}{l}\text { COMISSÃO } \quad \text { DE } \\
\text { AVALIAÇÃO }\end{array}$ & 4 & $\begin{array}{l}\text { Avaliação } \\
\text { individual } \\
\text { (por parte } \\
\text { de cada } \\
\text { membro da } \\
\text { comissão) }\end{array}$ & $\begin{array}{l}\text { Inventário conceitual e físico; } \\
\text { Projeto individual de valoração; }\end{array}$ \\
\hline $\begin{array}{l}\text { COMISSÃO } \quad \text { DE } \\
\text { AVALIAÇÃO }\end{array}$ & 5 & $\begin{array}{l}\text { Avaliação } \\
\text { colegiada }\end{array}$ & $\begin{array}{l}\text { Inventário conceitual e físico; } \\
\text { Projetos individuais de valoração; } \\
\text { Ata de reunião da comissão; } \\
\text { Proposta de Tabela de } \\
\text { Temporalidade; }\end{array}$ \\
\hline ARQUIVO & 6 & $\begin{array}{l}\text { Solicitação } \\
\text { de } \\
\text { aprovação }\end{array}$ & $\begin{array}{l}\text { Proposta de } \\
\text { Temporalidade; }\end{array}$ \\
\hline
\end{tabular}




\begin{tabular}{|c|c|c|c|}
\hline Entidade & Fases & Operação & Documentação \\
\hline $\begin{array}{l}\text { UNIDADE } \\
\text { ADMINISTRATIVA }\end{array}$ & 7 & $\begin{array}{l}\text { Resposta } \\
\text { da unidade } \\
\text { administrati } \\
\text { va sobre o } \\
\text { projeto de } \\
\text { tabela de } \\
\text { temporalida } \\
\text { de }\end{array}$ & $\begin{array}{l}\text { Ofício de solicitando aprovação da } \\
\text { proposta de Tabela de } \\
\text { Temporalidade pela unidade } \\
\text { administrativa produtora dos } \\
\text { documentos (enviado pelo Arquivo); } \\
\text { Ofício encaminhando relatório de } \\
\text { resposta da unidade administrativa } \\
\text { sobre a tabela de temporalidade; } \\
\text { Relatório da unidade administrativa } \\
\text { sobre projeto da tabela de } \\
\text { temporalidade; }\end{array}$ \\
\hline ARQUIVO & 8 & $\begin{array}{l}\text { Verificação } \\
\text { do Relatório }\end{array}$ & \\
\hline ARQUIVO & 9 & $\begin{array}{l}\text { Confecção } \\
\text { da versão } \\
\text { final da } \\
\text { Tabela de } \\
\text { Temporalid } \\
\text { ade }\end{array}$ & $\begin{array}{l}\text { Plano de classificação;; } \\
\text { Proposta de tabela de } \\
\text { temporalidade, (incluindo legislação } \\
\text { que embasa as decisões sobre os } \\
\text { prazos de guarda); }\end{array}$ \\
\hline ARQUIVO & 10 & $\begin{array}{l}\text { Pedido de } \\
\text { Relatório }\end{array}$ & $\begin{array}{l}\text { Proposta de tabela de } \\
\text { temporalidade; } \\
\text { Ofício solicitando manifestação da } \\
\text { direção sobre a proposta de tabela } \\
\text { de temporalidade; }\end{array}$ \\
\hline DIREÇÃO & 11 & $\begin{array}{l}\text { Manifestaçã } \\
\text { o da direção } \\
\text { do } \\
\text { organismo }\end{array}$ & $\begin{array}{l}\text { Ofício solicitando manifestação da } \\
\text { direção sobre a proposta de tabela } \\
\text { de temporalidade; } \\
\text { Proposta de tabela de } \\
\text { temporalidade; } \\
\text { Relatório de manifestação da direção } \\
\text { do organismo (aprovando, } \\
\text { rejeitando, solicitando ajustes); }\end{array}$ \\
\hline ARQUIVO & 12 & $\begin{array}{l}\text { Apreciação } \\
\text { do relatório }\end{array}$ & \\
\hline
\end{tabular}

Fonte: Adaptado ${ }^{3}$ de Hernandez Olivera e Moro Cabero (2002, tradução nossa).

As entidades envolvidas são direção da instituição, arquivo, membros da comissão de avaliação (de forma individual e coletiva) e a unidade administrativa

3 A adaptação do quadro levou em conta a distinção feita na Espanha entre "reglas de conservación" (referente a cada órgão) e "calendário de conservación" (o instrumento oficial de destinação que incorpora todas as reglas), dependendo da região autônoma. (HERNÁNDEZ OLIVERA, 2005). Substituiu-se a referência a regras por projeto individual de valoração. 
de origem dos documentos em processo de avaliação.

Nesse sentido, chama-se a atenção para a Fase 3 - Pesquisa preliminar. De acordo com Hernandez Olivera e Moro Cabero (2002), a fase de pesquisa preliminar é de responsabilidade do arquivo e consiste em reunir toda informação necessária sobre as séries documentais que serão avaliadas:

En primer lugar, se debe reunir información sobre el contexto en que se ha creado la documentación, dado que esta refleja los valores, tendencias y funciones de la entidad responsable por su producción. En segundo lugar, información sobre la propia documentación, su origen, función, tramitación, contenidos. Por último, se deberán recopilar todas las valoraciones, propuestas de expurgo o reglas de conservación que se hayan elaborado sobre la misma tipología de documentos en otras instituciones o entidades (HERNANDEZ OLIVERA; MORO CABERO, 2002, p. $62)$.

Para obter as informações referidas acima, os autores propõem a construção de um inventário conceitual e físico. A parte conceitual é composta pela denominação da instituição e seu tipo, vinculações, características, história (datas e eventos relevantes), estrutura, marcos normativos, legislação que afeta a missão e operações da instituição, organizações parceiras ou relacionadas, normas internas da instituição, atividades e setores relacionados às mesmas. A parte física está mais direcionada aos aspectos materiais de cada série documental, bem como a suas quantidades e prazos de guarda já praticados.

Observa-se que a representação de funções realizada com o auxílio da ISDF permite dar conta da maior parte das informações necessárias para a pesquisa preliminar, especialmente aquela necessária ao aspecto conceitual do inventário, conforme proposto no modelo de Hernandez Olivera e Moro Cabero (2002). Como parte do conjunto de documentos que embasará as decisões sobre os prazos de guarda, a descrição de funções pode subsidiar, ainda, a avaliação individual e a avaliação colegiada dos membros das comissões de avaliação (Fases 4 e 5). Relacionando as áreas da ISDF com o inventário conceitual, que será base para a construção da avaliação, o Quadro 3 mostra que há diversas características intrínsecas aos dois: 
Quadro 3 - Áreas da ISDF x Inventário Conceitual

\begin{tabular}{|c|c|}
\hline Área & Inventário Conceitual \\
\hline ÁREA DE IDENTIFICAÇÃO & $\begin{array}{l}\text { Denominação da instituição e seu tipo; } \\
\text { Estrutura; }\end{array}$ \\
\hline ÁREA DE CONTEXTUALIZAÇÃO & $\begin{array}{l}\text { História (datas e eventos relevantes) } \\
\text { Características; } \\
\text { Legislação; } \\
\text { Marcos normativos; } \\
\text { Normas internas da instituição; }\end{array}$ \\
\hline ÁREA DE RELACIONAMENTOS & $\begin{array}{l}\text { Organizações parceiras ou relacionadas; } \\
\text { Atividades e setores relacionados às } \\
\text { mesmas; }\end{array}$ \\
\hline ÁREA DE CONTROLE & ------- \\
\hline
\end{tabular}

Fonte: Elaboração das autoras (2019).

Com a apresentação do quadro ficam evidentes características comuns à ISDF e ao inventário conceitual, parte do processo de avaliação de documentos. A área de controle é a única em que não se observam características diretas com o inventário conceitual. Porém, se considerar que a atribuição da criação desse inventário é da comissão permanente de avaliação, o controle será feito pela mesma, demonstrando aspectos comuns em sua totalidade.

\section{CONSIDERAÇÕES FINAIS}

É possivel identificar distintos diálogos sendo estreitados entre a Arquivologia e a ORIC, principalmente no tocante às funções de descrição e classificação. Aqui se procurou demonstrar que para além destas, e a partir da ISDF, a avaliação também possui relações com a ORIC.

Inicia-se pela ISDF e a avaliação de documentos. Ao aplicar a ISDF, fazendo a descrição das funções da instituição, e em contraponto com o inventário conceitual que é uma das etapas do processo de avaliação (HERNANDEZ OLIVERA; MORO CABERO, 2002), se observa distintas semelhanças nos dois processos, o que demonstra que a ISDF e a função de avaliação podem estar intimamente relacionadas.

Para tanto, considera-se que a representação da informação que resulta 
da ISDF pode servir de base para a construção de um instrumento de destinação de documentos, especialmente, na fase de levantamentos preliminares, levando em conta os procedimentos técnicos da avaliação propostos por Hernandez Olivera e Moro Cabero (2002), que subsidiarão as decisões dos arquivistas e membros da comissão de avaliação. Nesse sentido, a tabela de temporalidade, também pode ser entendida como uma forma de representação da informação, em grande parte por ser consequência da função de classificação arquivística, onde serão atribuídos códigos, classes, ou seja, representações da informação.

Assim, acredita-se que a relação entre a representação da informação e a função de avaliação arquivística foi demonstrada, evidenciando que a ORI pode contribuir para o desempenho de outras funções arquivísticas, neste caso, a avaliação. Sugere-se novas pesquisas e a análise de outros modelos e teorias, que talvez revelem necessidade de outras normas e padrões.

\section{REFERÊNCIAS}

ALVES, B. H.; OLIVEIRA, E. F. T. de. O desenvolvimento do domínio da "organização do conhecimento" no contexto da Ciência da Informação a partir da ISKO-Brasil. Brazilian Journal of Information Studies: Research Trends, Marilia, v. 10, n. 2, p. 103-108, 2016. Disponível em: http://www2.marilia.unesp.br/revistas/index.php/bjis/article/view/5985. Acesso em 28 mar. 2019.

BARROS, T. H. B. A indexação e a Arquivística: aproximações iniciais no universo teórico da organização e representação do conhecimento. Encontros Bibli - Revista Eletrônica de Biblioteconomia e Ciência da Informação, Florianópolis, v. 21, n. 46, p. 33-44, mai./ago. 2016. Disponível em: https://periodicos.ufsc.br/index.php/eb/article/view/42393. Acesso em: 02 out. 2018.

BRÄSCHER, M.; CAFÉ, L. Organização da informação ou organização do conhecimento?. In: ENCONTRO NACIONAL DE PESQUISA EM CIÊNCIA DA INFORMAÇÃO, 9., 2008, São Paulo. Anais [...]. São Paulo: ANCIB/USP, 2008.

BRASIL. Lei $\mathbf{n}^{0} 8.159$ de 08 de janeiro de 1991. Dispõe sobre a política nacional de arquivos públicos e privados e dá outras providências. Brasília, 08 jan. 1991. Disponível em: http://www.planalto.gov.br/ccivil_03/leis/L8159.htm. Acesso em: 17 mar. 2019. 
COOK, T. Entrevista - Terry Cook [Português]. InCID: Revista de Ciência da Informação e Documentação, Ribeirão Preto, v. 3, n. 2, p. 142-156, jul./dez., 2012. Disponível em: http://www.revistas.usp.br/incid/article/view/48658/52729. Acesso em: 17 mar. 2019.

COOK, T. Appraisal Methodology: Macro-appraisal and functional analysis part A: Concepts and Theory. Ottawa: Library and archives Canada, 2001, $11 \mathrm{p}$. Disponível em: https://www.bac-lac.gc.ca/eng/services/government-informationresources/disposition/Documents/MacroappraisalPartA.pdf. Acesso em: 05 out. 2018.

COOK, T. Macroappraisal in theory and practice: origins, characteristics, and implementation in Canada, 1950-2000. Archival Science, Canadá, v. 5, p. 101-161, dez., 2005. Disponível em: http://web.utk.edu/ lbronsta/cook.pdf. Acesso em: 03 out. 2018.

CONSELHO INTERNACIONAL DE ARQUIVOS (CIA). ISDF: Norma internacional para descrição de funções. Arquivo Nacional: Rio de Janeiro, 2008. Disponível em: http://conarq.gov.br/images/publicacoes_textos/ISDF.pdf. Acesso em: 09 out. 2018.

DAHLBERG, I. Knowledge Organization: a new Science? Knowledge Organization: Germany, v. 33, n. 1. p.11-19, 2006.

DURANTI, L. Origin and development of the concept of archival description. Archivaria, Ottawa, v. 35, p. 47-54, 1993.

GOMES, H. E. Marcos históricos e teóricos da organização do conhecimento. Informação \& Informação, Londrina, v. 22, n. 2, p. 33-66, out. 2017. Disponível em: http://www.uel.br/revistas/uel/index.php/informacao/article/view/31442/21990. Acesso em: 28 mar. 2019.

HERNANDEZ OLIVERA, L.; MORO CABERO, M. Procedimientos de valoración documental. San Cristóbal de la Cuesta: Asociación de Archiveros de Castilla y León, 2002.

HJØRLAND, B. What is Knowledge Organization (KO)? Knowledge Organization, Germany, v. 35, n. 2, p. 86-101, 2008.

\section{LLANES PADRÓN, D. La descripción archivística en los tiempos} posmodernos: conceptos, principios y normas. Marília: Oficina Universitária; São Paulo: Cultura Acadêmica, 2016.

MAKOWIECKY, S. Representação - a palavra, a idéia, a coisa. Cadernos de pesquisa interdisciplinar em Ciências Humanas, Florianópolis, v. 4, n. 57, dez. 2003. Disponível em:

https://periodicos.ufsc.br/index.php/cadernosdepesquisa/article/view/2181/4439 . Acesso em: 28 mar. 2019. 
NATIONAL ARCHIVES OF AUSTRALIA. How we selecting national archives. Disponível em: http://www.naa.gov.au/informationmanagement/selecting-national-archives/. Acesso em: 28 mar. 2019.

RIBEIRO, F. Novos caminhos da avaliação de informação. Arquivística.net, Rio de Janeiro, v.1, n. 2, p. 53-74, jul./dez., 2005. Disponível em: http://www.brapci.inf.br/index.php/article/download/6595. Acesso em: 28 mar. 2019.

ROUSSEAU, J.; COUTURE, C. Os fundamentos da disciplina arquivística. Glossário. Lisboa. Publicações Dom Quixote, 1998, 360p.

SCHELLENBERG, T. R. Arquivos modernos: princípios e técnicas. 6. ed. Rio de Janeiro: FGV, 2006, 388p.

SOUSA, R. T. B. de. A classificação como função matricial do que-fazer arquivístico. In: SANTOS, V. B. dos; INNARELLI, H. C.; SOUSA, R. T. B. de (Orgs.). Arquivística: temas contemporâneos. Distrito Federal: SENAC, 2008. p. 77-172.

TOGNOLI, N. B.; GUIMARÃES, J. A. C. A organização do conhecimento arquivístico: perspectivas de renovação a partir das abordagens científicas canadenses. Perspectivas em ciência da informação, Belo Horizonte, v. 16, n. 1, p. 21-44, jan./mar., 2011. Disponível em: http://portaldeperiodicos.eci.ufmg.br/index.php/pci/article/view/1084/832. Acesso em: 28 mar. 2019.

VITAL, L. P.; MEDEIROS, G. M. de; BRÄSCHER, M. Classificação e descrição arquivísticas como atividades de organização e representação do conhecimento. Brazilian Journal of Information Science: Research Trends, Marília, v. 11, n. 4, p. 40-46, 2017. Disponível em: http://www2.marilia.unesp.br/revistas/index.php/bjis/article/view/7507. Acesso em: 28 mar. 2019.

\title{
DIALOGUES BETWEEN THE ARCHIVAL APPRAISAL FUNCTION AND THE REPRESENTATION OF THE INFORMATION
}

\begin{abstract}
Introduction: With the change of its object of study, from set of documents to the set of organic information, the Archivology assists new theoretical-methodological dialogues with different disciplines that also have the information object, such as Information Science and Organization of Knowledge and Information. In this perspective, the present research starts from the problematic of analyzing if the Organization and Representation of the Information can be observed within the Arquivologia, mainly in relation to the archival function of evaluation of documents. Objective: To demonstrate relationships between the archival evaluation function and the information representation, from ISDF.
\end{abstract}


Methodology: exploratory and qualitative research. Results: when making the parallel between document evaluation, ISDF and Information Representation it is possible to identify that the ISDF contributes to the archival evaluation, from the description of the functions of the institution, described here, understood here as representation of the archival information. Conclusion: this research demonstrated that the dialogues can be observed and sought to instigate the academic community to the subject and to the development of new research related to the evaluation process and the representation of the information.

Descriptors: Information organization. Archival science. Archival appraisal. International Standard for Describing Functions.

\title{
DIALOGOS ENTRE LA FUNCIÓN DE VALORACIÓN ARCHIVÍSTICA Y LA REPRESENTACIÓN DE LA INFORMACIÓN
}

\begin{abstract}
RESUMEN
Introducción: Con la alteración de su objeto de estudio, de conjunto de documentos para el conjunto de informaciones orgánicas, la Archivología asiste a nuevas interlocuciones teórico-metodológicas con distintas disciplinas que también poseen como objeto la información, como la Ciencia de la Información y la Organización del Conocimiento e Información. En esta perspectiva, la presente investigación parte de la problemática de analizar si la Organización y la Representación de la Información pueden ser observadas dentro de la Archivología, principalmente en lo que se refiere a la función archivística de valoración de documentos. Objetivo: Demostrar relaciones entre la función de valoración archivística y la representación de la información, a partir de la ISDF. Metodología: investigación exploratoria y cualitativa. Resultados: al hacer el paralelo entre la valoración de documentos, la ISDF y la Representación de la Información es posible identificar que la ISDF contribuye a la valoración archivística, a partir de la descripción de las funciones de la institución, descripción que, entendida aquí como representación de la información archivística. Consideraciones: esta investigación demostró que los diálogos pueden ser observados y procuró instigar a la comunidad académica para el tema y para el desarrollo de nuevas investigaciones relacionadas al proceso de valoración y la representación de la información.
\end{abstract}

Descriptores: Organización de la información. Archivística. Valoración archivística. Norma Internacional de Descripción de Funciones. 